\title{
Experimental aspects of cobalt cardiomyopathy
}

\author{
G. Rona \\ From the Bio-Research Laboratories and Pathological Institute, \\ McGill University, Montreal, Quebec, Canada
}

All chambers of the heart are affected in experimental cobalt cardiomyopathy, with atrial predilection. The primary morphological alteration is mitochondrial damage that possibly reflects an enzymatic block of oxidative decarboxylation at pyruvate and ketogluterate levels. In acute cobalt toxicity chelation of calcium may also be a contributory factor, resulting in deficient utilization of high-energy phosphates. Experimental cobalt cardiomyopathy requires preconditioning factors: protein deficiency appears to be one of them. Vegetative polypoid endocarditis is an important accompaniment in the model used, suggesting that in rats on a protein deficient diet cobalt produced endothelial damage in addition to a cardiocyte injury.

In 1965 investigators in Quebec (Morin et al., 1967) and Omaha (McDermott et al., 1966) observed an endemic cardiomyopathy in heavy beer drinkers. Though epidemiological studies suggested a multicausal origin, cobalt, a beer additive, appeared to play a major part (Kesteloot et al., 1968). Since the Quebec outbreak, studies on experimental animals have been carried out in collaboration with Dr. C. I. Chappel to reproduce the characteristic vacuolar and dystrophic 'myocardosis' of humans (Bonenfant, Miller, and Roy, 1967; Rona, 1968) and to gain an insight into the pathogenesis of this condition, using cobalt administration alone or in combination with hormonal and nutritional factors.

\section{Methods and results}

Male Sprague-Dawley rats weighing 200-250 g. were used. Cobalt sulphate alone, administered orally in high dosage (100 mg./kg.), was cardiotoxic. However, the incidence of myocardial changes was low as the rats died prematurely in systemic circulatory failure. The lesion consisted mainly of fatty change, contraction bands, and hyaline myofibre necrosis (Fig. I). This acute cardiotoxicity of cobalt was probably related to a competitive inhibition of $\mathrm{Ca}$ (Kaufmann and Fleckenstein, 1965) that resulted in an inability of cardiac muscle cells to utilize high energy phosphate and to sustain mechanical tension in the state of excitation.

As cobalt inhibits the biosynthesis of thyroxin and cobalt administration results in thyroid alterations (Bonenfant et al., 1967),
FIG. I 'Hyalin necrosis' of cardiac muscle cell with contraction bands (bottom right). Rat treated daily with $100 \mathrm{mg} . / \mathrm{kg}$. cobalt sulphate. (Electron micrograph: uranyl acetate and lead citrate staining. $\times 6,800$.)

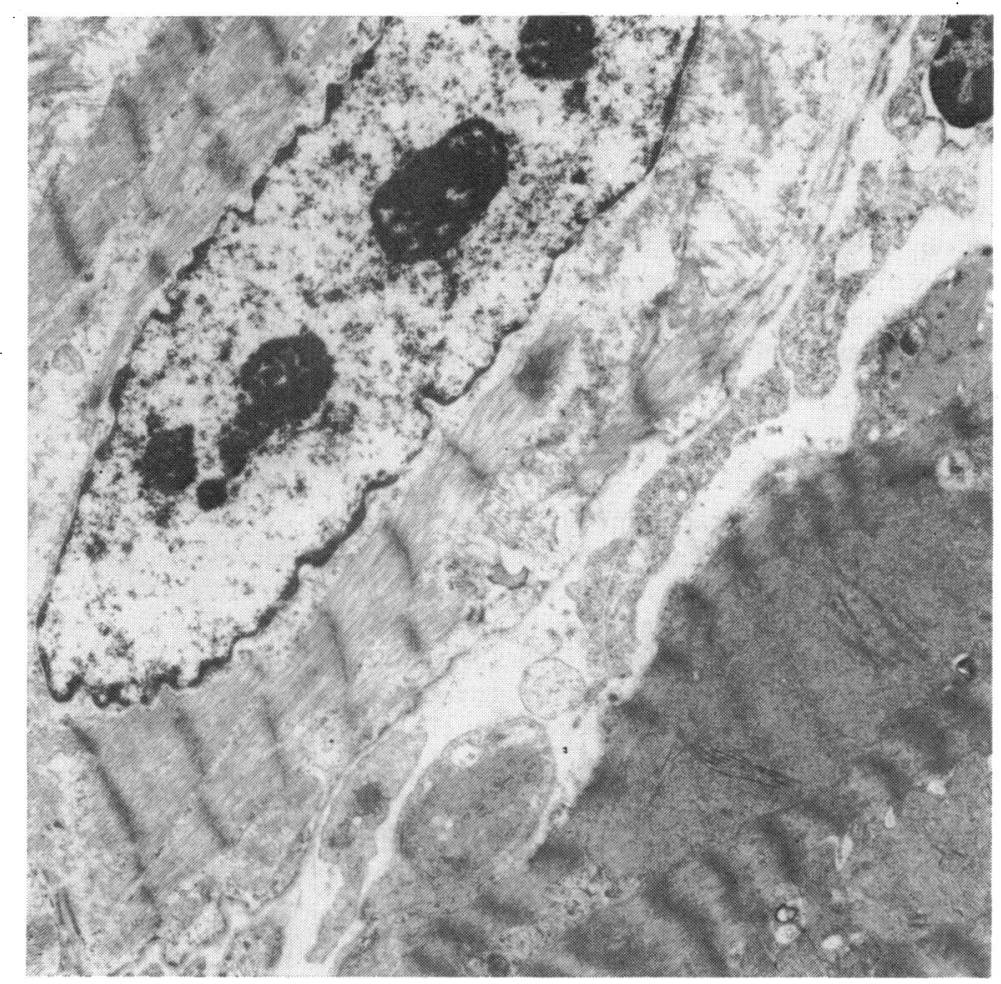


the predisposing role of hypothyroidism was considered. Though both prior treatment with propylthiouracil and thyroidectomy aggravated the myocardial changes of cobalttreated rats, no distinct dystrophic-vacuolar cardiomyopathy was produced. The same results were obtained after the simultaneous administration of a sympathomimetic drug (isoprenaline) and cobalt, or by a combination of thiamine deficiency and cobalt.

A combination of protein-deficient diet and cobalt administration was also studied. In these experiments cobalt sulphate, containing from 4.0 to $12.5 \mathrm{mg}$. $/ \mathrm{kg}$. cobalt ion, was given daily in $\mathrm{r} \cdot 0 \mathrm{ml}$. distilled water by gavage to 280 rats for two weeks. Before this procedure the rats were preconditioned for Io days by protein restriction. Severe cardiomyopathy occurred in rats receiving the low protein diet consisting of 4 per cent casein and treated with I2. $5 \mathrm{mg}$. $/ \mathrm{kg}$. cobalt ion. All chambers of the heart were involved; apparently the atrial myocardium underwent more extensive damage than that of the ventricles. At the light microscopical level the swollen cardiac muscle cells contained coarse irregular myofibrils. Hydropic vacuoles alternated with stippled basophilic areas. The latter change was particularly prominent in $\mathrm{I} \mu \mathrm{m}$. thick sections of Epon embedded material stained with toluidine blue (Fig. 2). In advanced cases there was partial or complete lysis of the muscle cells leaving empty sarcolemmal sheaths behind. The most ubiquitous fine structural feature of the myocardial lesions was swelling of the mitochondria, with decreased matrical density and, finally, disruption of the cristae and the outer membrane (Fig. 3). In addition, dilatation of sarcoplasmic reticulum and intrasarcoplasmic oedema were noted. The myofilaments were pushed to the periphery of the cell or occupied a perinuclear position.

\section{Discussion}

These histological and fine structural alterations correlate well with the metabolic derangement of protein deficiency (Svoboda, Grady, and Higginson, 1966) and cobalt toxicity (Grice et al., 1969; Hall and Smith, 1968). Cobalt interferes with myocardial energy metabolism, as it irreversibly chelates with the dithiol form of lipoic acid (Dingle et al., 1962; Webb, 1962), inactivating the coenzyme required for the oxidative decarboxylation of pyruvate to acetyl coenzyme $A$ and alpha ketoglutarate to succinate (Alexander, 1969). Pyruvate and lactate accumulation in the mitochondria increases osmotic pressure

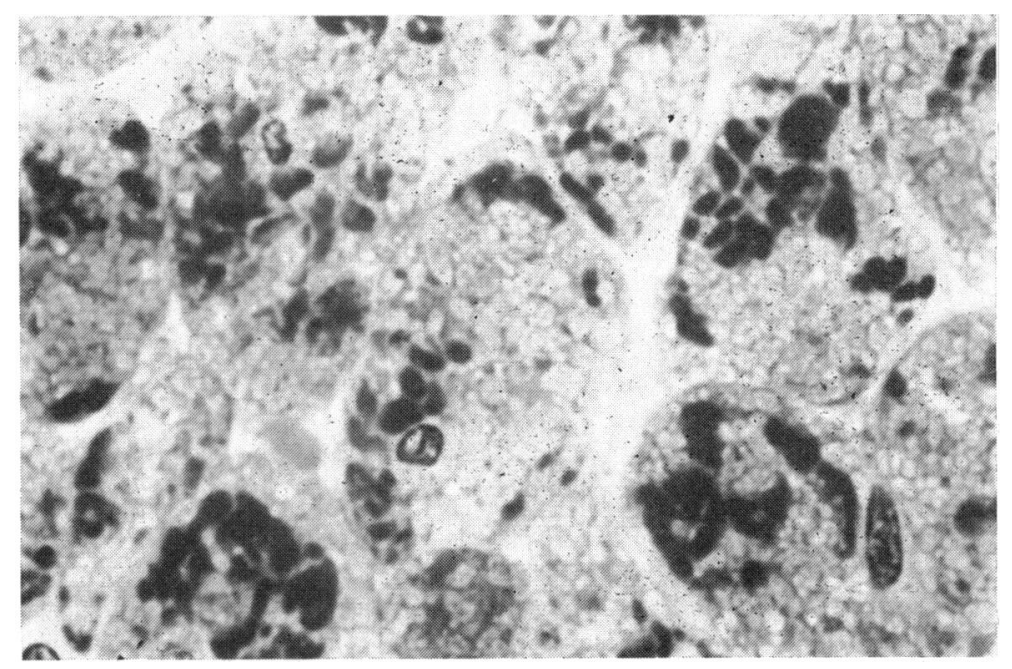

FIG. 2 Pale perinuclear areas of cardiocytes represent swollen mitochondria. (Epon embedded I $\mu \mathrm{m}$. thick section, stained with toluidine

blue. $\times 1280$.)

FIG. 3 Electron microscopic presentation of swollen mitochondria, dilated sarcoplasmic reticulum, and intrasarcoplasmic oedema. $(\times 20,800$. $)$

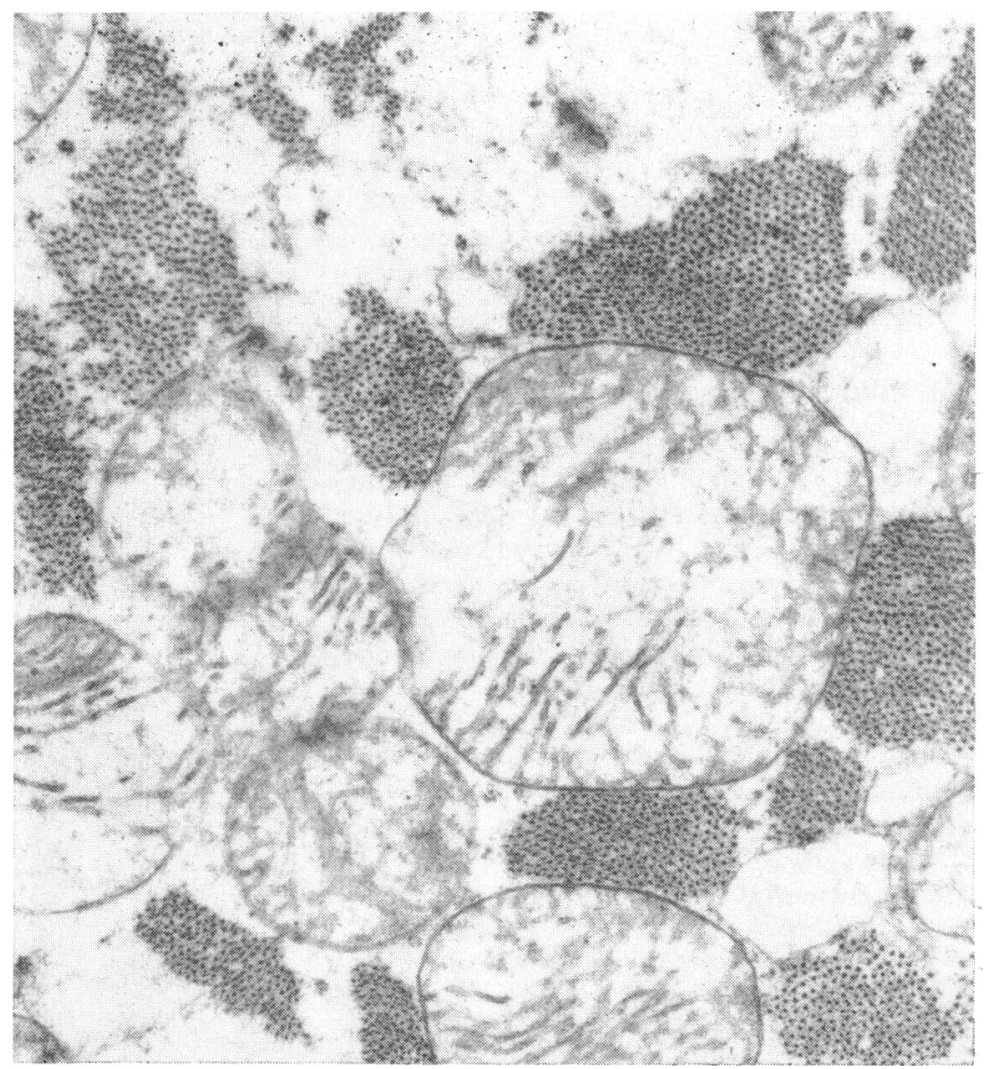


FIG. 4 Electron dense intramitochondrial particles represent cobalt-protein complexes. $(\times 16,300$.

and results in water binding, oedema, and finally structural disruption. Aminoacids combine readily with cobalt and prevent its chelation with sulphydryl groups of the myocardial tissue (Alexander, 1969; Wiberg et al., 1969). Protein deficiency blocks this protective mechanism. Whereas the fine structural changes the mitochondria presented are nonspecific, a pathognomonic feature of cobalt intoxication was the appearance of dense osmophilic intramitochondrial particles, measuring $0.3-0.4 \mu \mathrm{m}$. in diameter (Fig. 4), considered to represent cobalt-protein complexes (Knieriem and Herbertz, 1969; Kasperek, Siller, and Knieriem, 1969). These differed from the fine granular intramitochondrial calcium deposit described in a variety of myocardial injuries.

In addition to the myocardial lesion, polypoid vegetative endocarditis developed in 10-35 per cent of rats receiving the lowprotein diet and treated with cobalt. The mitral valve was affected predominantly (Fig. 5), but vegetations also occurred occasionally on the aortic and tricuspid valves and on the parietal endocardium. A non-necrotizing granulomatous inflammatory process developed around the vegetations (Fig. 6). Blood cultures from these rats were negative. Electron microscopical findings consisted of endothelial cell alteration leading to endothelial discontinuity that allowed platelets to be carried into the subendothelial stroma. In the depth of the valve there was polymerized fibrin among proliferating fibroblasts (Fig. 7). Though it is conceivable that endothelial damage may be the primary factor in the genesis of endocarditis, platelet conglutination may also be important, since oxidation of the free SH groups on the platelet surface, a step in platelet conglutination (Skảlhegg, Hellem, and Odegaard, 1964), may be affected by cobalt and protein deficiency.

FIG. 5 Gross presentation of polypoid endocarditis in the mitral valve of a rat on protein-deficient diet treated with $12.5 \mathrm{mg}$. $/ \mathrm{kg}$. cobalt ion daily.
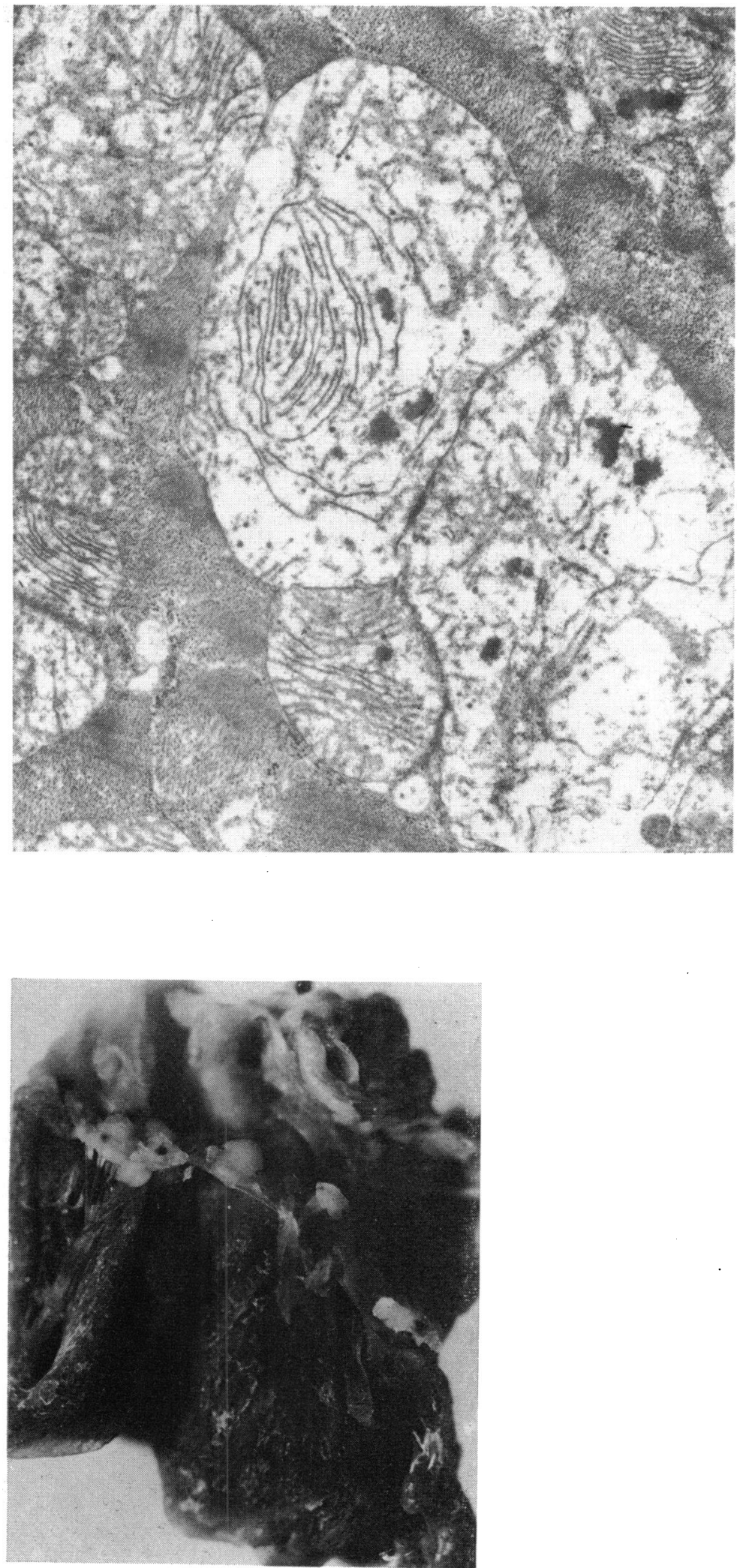


\section{References}

Alexander, C. S. (1969). Editorial. Cobalt and the heart. Annals of Internal Medicine, 70, $4 \mathrm{I}$ I.

Bonenfant, J. L., Miller, G., and Roy, P. E. (1967). Quebec beer-drinkers' cardiomyopathy: pathological studies. Canadian Medical Association fournal, 97, 910.

Dingle, J. T., Heath, J. C., Webb, M., and Daniel, M. (1962). The biological action of cobalt and other metals. II. The mechanism of the respiratory inhibition produced by cobalt in mammalian tissues. Biochimica et Biophysica Acta, 65, 34 .

Grice, H. C., Munro, I. C., Wiberg, G. S., and Heggtveit, H.A. (1969). The pathology of experimentally induced cobalt cardiomyopathies. A comparison with beer drinkers' cardiomyopathy. Clinical Toxicology, 2, 273.

Hall, J. L., and Smith, E. B. (1968). Cobalt heart disease. An electron microscopic and histochemical study in the rabbit. Archives of Pathology, 86, 403.

Kasperek, K., Siller, V., and Knieriem, H. J. (I969). Neutronenaktivierungsanalytische Bestimmung von Kobalt und Calcium bei der experimentellen Herzinsuffizienz durch Kobaltchlorid. Zeitschrift für die gesamte experimentelle Medizin, Zugleich Fortsetzung der Zeitschrift für experimentelle Pathologie und Therapie, 150, 316.

Kaufmann, R., and Fleckenstein, A. (1965). Ca+tkompetitive elektro-mechanische Entkoppelung durch $\mathrm{Ni}^{++}$- und $\mathrm{Co}^{++}-$Ionen am Warmblütermyokard. Pflügers Archiv für die gesamte Physiologie des Menschen und der Tiere, 282, 290.

Kesteloot, H., Roelandt, J., Willems, J., Claes, J. H., and Joossens, J. V. (I968). An enquiry into the role of cobalt in the heart disease of chronic beer drinkers. Circulation, 37, 854

Knieriem, H. J., and Herbertz, G. (1969). Elektronenmikroskopische Befunde sowie photometrische und aktivierungsanalytische Ergebnisse bei experimenteller Herzinsuffizienz durch Kobaltchlorid. Virchows Archiv Abteilung B. Zellpathologie, $2,32$.

McDermott, P. H., Delaney, R. L., Egan, J. D., and Sullivan, J. F. (1966). Myocardosis and cardiac failure in men. Fournal of the American Medical Association, 198, 253.

Morin, Y. L., Foley, A. R., Martineau, G., and Roussel, J. (1967). Quebec beer-drinkers' cardiomyopathy: forty-eight cases. Canadian Medical Association fournal, 97, 88I.

Rona, G. (1968). Endemic cardiomyopathy of beer consumers. Acta Morphologica Academiae Scientiarum Hungaricae, 16, 103.

Skålhegg, B. A., Hellem, A. J., and Ödegaard, A. E. (1964). Investigations on adenosine diphosphate (ADP) induced platelet adhesiveness in vitro. II Studies on the mechanism. Thrombosis et Diathesis Haemorrhagica, 1I, 305.

Svoboda, D., Grady, H., and Higginson, J. (1966). The effects of chronic protein deficiency in rats. II. Biochemical and ultrastructural changes. Laboratory Investigation, 15, 731 .

Webb, M. (1962). The biological action of cobalt and other metals. III. Chelation of cations by dihydrolipoic acid. Biochimica et Biophysica Acta, 65, 47.

Wiberg, G. S., Munro, I. C., Méranger, J. C., Morrison, A. B., Grice, H. C., and Heggtveit, H. A (1969). Factors affecting the cardiotoxic potential of cobalt. Clinical Toxicology, 2, 257.

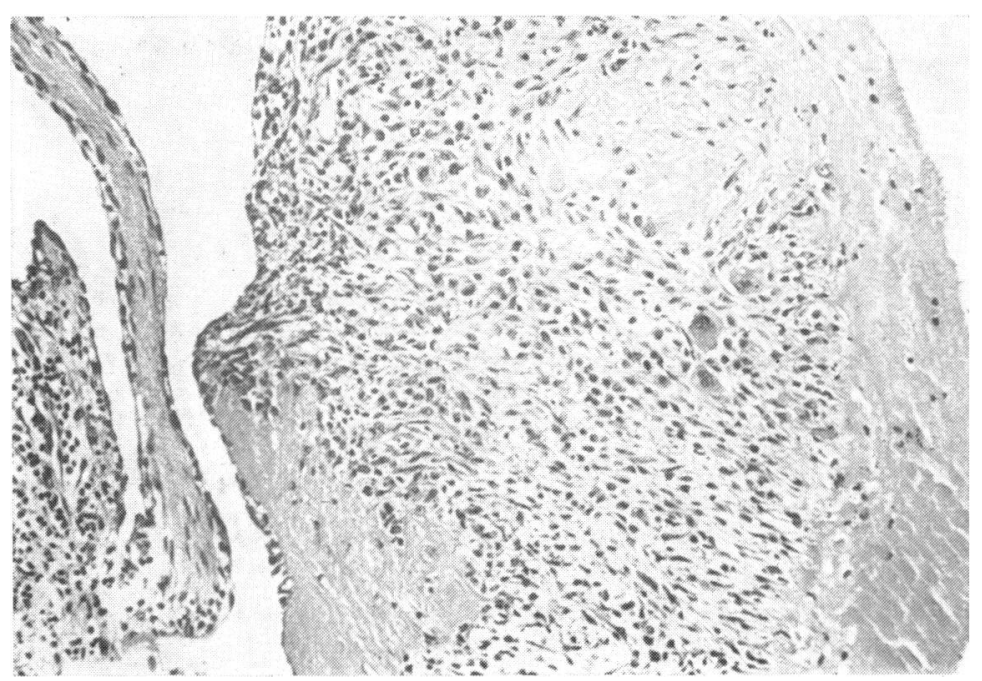

FIG. 6 Non-necrotizing granulomatous reaction around the valvular vegetations. (Haematoxylin and eosin. $\times 150$.

FIG. 7 Electron dense fibrin bundles among the proliferating cells of the valvular vegetations. $(\times 4,300$.

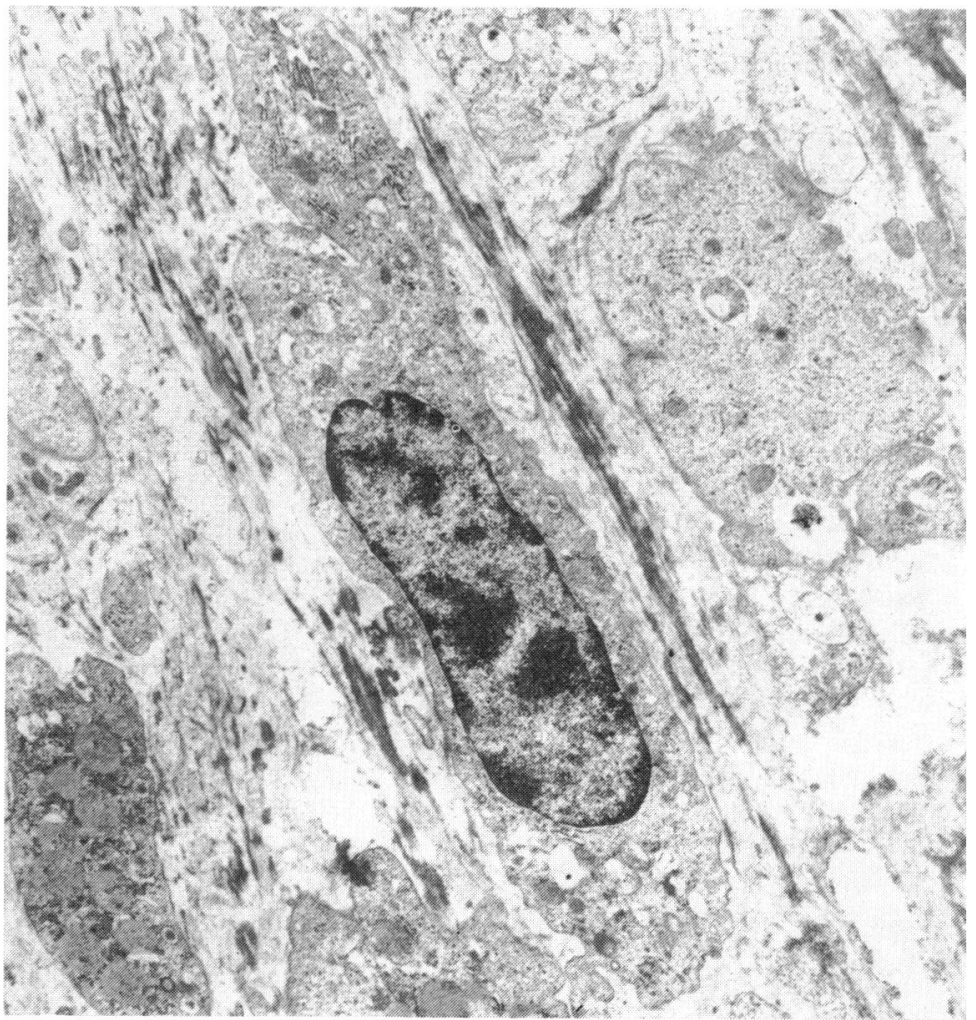

